\title{
BMJ Open Effect of balanced energy-protein supplementation during pregnancy and lactation on birth outcomes and infant growth in rural Burkina Faso: study protocol for a randomised controlled trial
}

\author{
Katrien Vanslambrouck (D) , ${ }^{1}$ Brenda de Kok (D) , ${ }^{1}$ Laeticia Celine Toe (D) , ${ }^{1,2}$ \\ Nathalie De Cock (D) , ${ }^{1}$ Moctar Ouedraogo (D) , ${ }^{3}$ Trenton Dailey-Chwalibóg (D) , \\ Giles Hanley-Cook (D) , Rasmané Ganaba (D) , ${ }^{3}$ Carl Lachat (D) , \\ Lieven Huybregts (D) , ${ }^{4}$ Patrick Kolsteren (i) ${ }^{1}$
}

To cite: Vanslambrouck K, de Kok B, Toe LC, et al. Effect of balanced energy-protein supplementation during pregnancy and lactation on birth outcomes and infant growth in rural Burkina Faso: study protocol for a randomised controlled trial. BMJ Open 2021;11:e038393. doi:10.1136/ bmjopen-2020-038393

- Prepublication history and additional materials for this paper is available online. To view these files, please visit the journal online (http://dx.doi. org/10.1136/bmjopen-2020038393).

Received 11 March 2020 Revised 06 January 2021 Accepted 23 January 2021

Check for updates

(c) Author(s) (or their employer(s)) 2021. Re-use permitted under CC BY. Published by BMJ.

For numbered affiliations see end of article.

\section{Correspondence to} Katrien Vanslambrouck; katrien.vanslambrouck@ugent. be and

Prof Carl Lachat; carl.lachat@ugent.be

\section{ABSTRACT}

Introduction Adequate nutrition during pregnancy is crucial to both mother and child. Maternal malnutrition can be the cause of stillbirth or lead to poor birth outcomes such as preterm delivery and small-for-gestationalage newborns. There is a probable positive effect of providing pregnant women a balanced energy-protein (BEP) food supplement, but more evidence is needed. The Mlcronutriments pour la SAnté de la Mère et de l'Enfant (MISAME) III project aims to improve birth outcomes and infant growth by testing a BEP supplement during pregnancy and lactation in rural Burkina Faso. This paper describes the study protocol.

Methods and analysis MISAME-III is a four-arm individually randomised efficacy trial implemented in six rural health centre catchments areas in the district of Houndé. Eligible pregnant women, aged between 15 and 40 years old and living in the study areas, will be enrolled. Women will be randomly assigned to one of the four study groups: (1) prenatal intervention only, (2) postnatal intervention only, (3) prenatal and postnatal intervention or (4) no prenatal or postnatal intervention. The intervention group will receive the BEP supplement and iron/folic acid (IFA) tablets, while the control group will only receive the IFA tablets following the national health protocol. Consumption will be supervised by trained village women on a daily basis by means of home visits. The primary outcomes are small-for-gestational age at birth and length-for-age z-score at 6 months of age. Secondary outcomes will be measured at birth and during the first 6 months of the infants' life. Women will be enrolled from October 2019 until the total sample size is reached. Ethics and dissemination MISAME-III has been reviewed and approved by the University Hospital of Ghent and the ethics committee of Centre Muraz, Burkina Faso. Informed consent will be obtained. Results will be published in relevant journals and shared with other researchers and public health institutions.

Trial registration number NCT03533712.
Strengths and limitations of this study

This trial will help to fill the evidence gap on the effect of balanced energy-protein (BEP) supplements in pregnant and lactating women on birth outcomes and infant growth.

- Formative research to select the most suitable BEP supplement ensured that the selected BEP is well accepted by the study population.

- The daily intake of BEP supplements and iron/folic acid tablets during pregnancy and lactation will be directly observed by study workers.

- This study will assess the impact of factorial combinations of prenatal and postnatal BEP on child growth to elucidate the relative importance of BEP during pregnancy and/or early lactation.

- Blinding of study participants and staff members will not be possible, as the supplements are identifiable.

\section{INTRODUCTION}

Pregnancy is a challenging period in the life of many women in low-income and middle-income countries (LMICs). Maternal mortality remains high, and many neonates suffer from premature delivery and/or intrauterine growth retardation, both in length and in weight accumulation. ${ }^{1}$ An indicator to measure neonatal growth is small-forgestational age (SGA). SGA is defined as a birth weight below the 10th percentile of a standard optimal reference population for a given gestational age and sex. ${ }^{2}$ SGA is often caused by growth restriction in the womb and has been associated with neonatal and postneonatal mortality. ${ }^{2}$ It has also been linked to an increased risk of morbidity later 
in life, especially non-communicable diseases. ${ }^{3}$ SGA affected 23.3 million term children in LMICs in 2012. ${ }^{4}$ Adequate nutrition during pregnancy is crucial for optimal maternal and newborn health, ${ }^{56}$ and maternal malnutrition has been associated with fetal growth restriction. ${ }^{7}$ An adequate dietary balance is necessary to ensure sufficient energy intake for adequate growth of the fetus. ${ }^{8}$ Unfortunately, maternal undernutrition remains a public health challenge in regions across sub-Saharan Africa and Asia. ${ }^{9} 10$

Several types of food supplements have been developed and evaluated over the past years. A positive effect of multiple micronutrient supplements (MMS) during pregnancy on birth outcomes has been found in previous studies. ${ }^{11}$ Keats et $a l^{11}$ concluded in their review that MMS during pregnancy gave a probable reduction in SGA and preterm births and can thus be used for future guidance. According to a multicountry randomised controlled trial (RCT) done in LMICs, a positive effect of lipidbased nutrient supplements on fetal growth-related birth outcomes can be seen when starting supplementation before conception or during the first trimester. ${ }^{12}$ Moreover, the latest evidence indicates a possible positive effect of providing pregnant women a balanced energyprotein (BEP) food supplement. ${ }^{513-15}$ In line with that evidence, the 2016 WHO's antenatal care guidelines state that pregnant women in undernourished populations should receive, depending on the context, BEP supplements to reduce the risk of stillbirth and SGA. ${ }^{6}$ Researchers, however, still highlight the limited amount of evidence and a need to evaluate the effect of balanced supplements on birth outcomes, such as SGA. ${ }^{513}$ Experimental trials of high-quality and large sample sizes, especially in undernourished pregnant women, are thus needed. ${ }^{13}$ Following this recommendation, compositional guidance for a ready-to-use food supplement for pregnant women was developed by the Bill and Melinda Gates Foundation (BMGF) in 2016. ${ }^{16}$

Two previous projects, MIcronutriments pour la SAnté de la Mère et de l'Enfant (MISAME) I and II, conducted in Burkina Faso, investigated the effect of supplementation during pregnancy and the effect on birth outcomes in infants. ${ }^{17} 18$ MISAME-I compared the effect of the UNICEF/WHO/UNU international multiple micronutrient preparation (UNIMMAP) with the effect of iron/folic acid (IFA) alone on fetal growth in a doubleblind RCT and concluded that UNIMMAP modestly but significantly increased fetal growth. ${ }^{17}$ The second study (MISAME-II) assessed the effect of a lipid-based nutrient supplement fortified with UNIMMAP compared with a UNIMMAP tablet during pregnancy in an openlabel, individually randomised controlled trial on birth anthropometry. It was found that combining energy with micronutrients during the prenatal phase led to larger birth lengths. ${ }^{18}$ Since MISAME-II used the UNIMMAP as a control, a complete assessment of the impact of the fortified lipid-based UNIMMAP was not possible. Therefore, MISAME-III will study the effect of a BEP

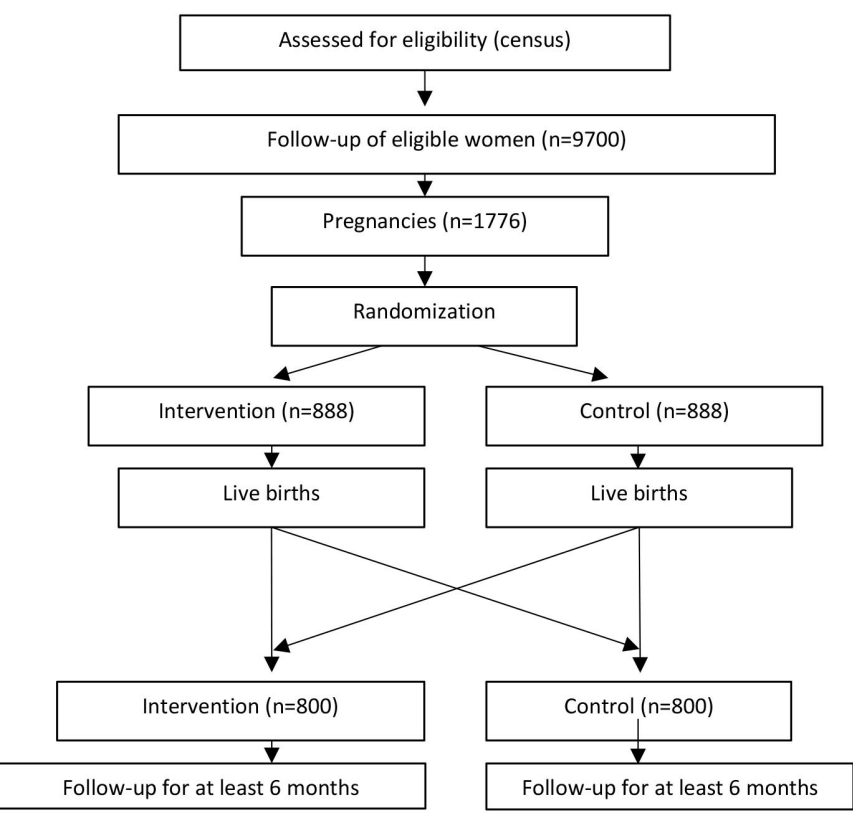

Figure 1 Study design of the randomised controlled trial.

supplementation, compared with a control group, and extend the supplementation postnatally to investigate the net contribution of prenatal and postnatal BEP supplementation on child linear growth up to 6 months of age.

In summary, the MISAME-III study hypothesises that: (1) providing women with a BEP supplement during pregnancy will decrease the incidence of SGA compared with the control group; and (2) providing them with a BEP supplement during the postnatal period will increase children's length by the age of 6 months compared with the control group.

\section{METHODS}

This protocol has been developed in accordance with the Standard Protocol Items: Recommendations for Interventional Trials guidelines (online supplemental file 1).

\section{MISAME-III study design}

The MISAME-III project is an individually randomised $2 \times 2$ factorial efficacy trial aiming to improve birth outcomes and infant growth in rural Burkina Faso by testing a BEP supplement during pregnancy and lactation (figure 1). At inclusion, pregnant women will be individually and randomly allocated to a prenatal intervention or control group and a postnatal intervention or control group. The intervention group will receive a daily BEP supplement to be consumed under supervision for the duration of pregnancy/lactation. Both intervention and control groups will receive the standard IFA tablet through the national antenatal care. In addition to the main trial, we propose a number of substudies to test specific hypotheses in a subsample of pregnant/lactating women and children. MISAME-III began with a formative study to identify the preferred product type for the provision of a fortified BEP supplement during the RCT. 


\section{Study setting}

The study will be conducted in the district of Houndé in Burkina Faso, a landlocked country situated in WestAfrica; similar to the previous MISAME studies, Burkina Faso has an infant mortality rate of 53 per 1.000 live births ${ }^{19}$ with an estimated Low Birth Weight (LBW) prevalence at $14 \%$ in $2013 .{ }^{20}$ The prevalence of SGA has been estimated to be between $32.2 \%$ and $41.6 \%$ in the district of Houndé. ${ }^{17}$ The Demographic and Health Survey of 2010 reported that $16 \%$ of women had a body mass index (BMI) below $18.5 \mathrm{~kg} / \mathrm{m}^{2}$, which indicates the presence of chronic energy deficiencies in the zone. ${ }^{21}$ The highest prevalence can be found in the Eastern region, where $31 \%$ of women have a BMI lower than $18.5 \mathrm{~kg} / \mathrm{m}^{2}$, that is, low BMI. ${ }^{22}$ Moreover, in particular, adolescent Burkinabèe girls between the age of 15 and 19 years have a low BMI, with an estimated prevalence of $23 \% .{ }^{23}$ Micronutrient deficiencies also remain a major problem in both infants and women of reproductive age in the country. ${ }^{23} 24$

The climate of the country is Sudano-Sahelian, with a dry season from October to March/April and a rainy season from May until September/October. The diet is essentially cereal based ${ }^{25}$ with maize as the main staple food. ${ }^{26}$

MISAME-III will be conducted in the same health district where the two previous MISAME studies were organised. The study villages are concentrated around six health centres, which are within an accessible range from the district hospital. A list of all study sites can be found on: www.misame3.ugent.be

\section{Study population and recruitment}

Women living in the study villages and aged between 15 and 40 years will be identified through a census. The villages were selected based on their accessibility and distance to the nearest health centre, number of facilitybased deliveries per year and their agricultural model as some households tend to reside on their fields during the harvest season. Trained village women (femme accompagnante (FA)), selected in collaboration with the community leaders, will visit the households every 5 weeks to ask about women's menstruation. In case of amenorrhoea, women will be sent to the nearest health centre for a pregnancy test and a first antenatal consultation by our project midwife when tested positive. An ultrasound examination will be completed soon after inclusion by the project medical doctor to assess gestational age. A baseline interview will also be done by the project interviewers to assess the household members' characteristics, household properties, water sanitation and hygiene (WASH) and household food security.

Inclusion criteria:

- Women between 15 and 40 years old at study inclusion.

- Confirmed pregnancy by a pregnancy test and ultrasound.

- Women who signed the informed consent form. Exclusion criteria:

- Pregnancies $>20$ weeks of gestational age.
- Women planning on leaving the area during their pregnancy.

- Women planning on delivering outside the study area.

- Women who are allergic to peanuts.

- Women with multifetal gestations (exclusion from analysis).

FAs will be informed by the project midwife when a participant has been included. FAs will visit pregnant women on a daily basis to distribute the BEP supplement and/or IFA tablet and to supervise consumption. During the postnatal period, FAs will distribute the supplements and IFA tablets to the intervention group on a daily basis until 6 weeks after birth. From that moment onwards, they will receive a week's worth of BEP supplements. The postnatal control group will receive the IFA tablets on a daily basis during the first 6 weeks after birth, and participants will thereafter be visited once a week (without any supplementation) to minimise the effect of home visits. The FA will inform women on the supplement's function, the importance of antenatal visits during pregnancy, maintaining a healthy diversified diet, the importance of delivering at a health facility, the importance of exclusive breast feeding and the introduction of complementary foods at the age of 6 months. Throughout the study, the FAs will be supervised by project interviewers. Supervision visits will be conducted using Lot Quality Assurance Sampling schemes and empty sachet counts to ensure that study participant are visited according to the project protocol.

\section{Manufacturing of 12 fortified BEP supplements and the formative study}

Twelve fortified BEP supplements were pretested before the start of the RCT during a formative research phase. Several food manufacturing companies were invited to produce ready-to-use BEP supplements following the compositional guidelines proposed during an expert meeting hosted by the $\mathrm{BMGF}^{16}$ in September 2016 (table 1). The BEP supplements had to be: (1) ready to consume, (2) not need a cold chain and (3) microbiologically stable.

Seven out of 12 supplements were characterised as sweet and five as savoury. Products were produced in different forms, including a biscuit, pillow, wafer, bar, paste, instant drink and soup.

In a first screening step of the formative study, the two most preferred BEP supplements were identified by using a combined evaluation approach consisting of a single meal test, sensory evaluation and focus group discussions, in a convenience sample of 40 pregnant women. In a next step, we compared the acceptability of the two preselected BEP supplements using a 10-week homefeeding study, with 80 pregnant women, to select to most preferred product for the RCT. We refer to both papers for detailed information. ${ }^{27} 28$

\section{Study intervention}

At inclusion, pregnant women will be randomly allocated to four different study groups: (1) prenatal intervention 


\section{Table 1 The compositional guidelines for macronutrients and micronutrients}

\begin{tabular}{|c|c|}
\hline $\begin{array}{l}\text { Nutrition } \\
\text { component }\end{array}$ & Target per serving \\
\hline Total energy & 250-500 kcal per serving. \\
\hline Fat content & $10 \%-60 \%$ of energy intake. \\
\hline Protein content & $\begin{array}{l}16 \mathrm{~g}(14-18 \mathrm{~g}) \text { with a digestible } \\
\text { indispensable amino acid score of } \geq 0.9 \text {. }\end{array}$ \\
\hline Carbohydrates & $\begin{array}{l}\text { Between } 45 \mathrm{~g} \text { and } 32 \mathrm{~g} \text { per } 100 \mathrm{~g} \text { (added } \\
\text { sucrose between } 20 \mathrm{~g} \text { and } 10 \mathrm{~g} \text { per } 100 \mathrm{~g} \text { ). }\end{array}$ \\
\hline Trans fats & $<1 \%$ of energy intake. \\
\hline Fatty acid & $\begin{array}{l}\text { (Optional): min of } 1.3 \mathrm{~g} \text { of } n-3 \text { or } \\
300 \mathrm{mg} \text { docosahexaenoic acid } \\
\text { (DHA)+eicosapentaenoic acid (of which } \\
200 \mathrm{mg} \text { DHA) to achieve a healthy } n-6 \text { : ratio } \\
\text { of the supplement of } 5: 1 \text {. }\end{array}$ \\
\hline Micronutrients & $\begin{array}{l}\text { Vitamin A, D, E, K, B1 (thiamin), B2 } \\
\text { (riboflavin), B3 (niacin), B6 (pyridoxine), B9 } \\
\text { (folate), B12 and C; minerals: iron, zinc, } \\
\text { iodine, calcium, phosphorous, copper and } \\
\text { selenium. }\end{array}$ \\
\hline \multirow[t]{2}{*}{ Optionally } & $\begin{array}{l}\text { Pantothenic acid, manganese, potassium, } \\
\text { biotin and choline will be included. }\end{array}$ \\
\hline & $\begin{array}{l}\text { The final composition of the product will be } \\
\text { determined by the selected product as the } \\
\text { manufacturing process will influence the } \\
\text { macronutrient composition. }\end{array}$ \\
\hline
\end{tabular}

only, (2) postnatal intervention only, (3) prenatal and postnatal intervention or (4) no prenatal and no postnatal intervention. Prenatal and postnatal supplementation will start right after inclusion and birth, respectively. The prenatal intervention group will receive the BEP supplement and IFA, while the control group will receive IFA tablets alone. The IFA tablets contain $65 \mathrm{mg}$ iron and $0.4 \mathrm{mg}$ folic acid. The postnatal intervention group will receive the BEP supplement for 6 months in combination with the IFA tablets for 6 weeks following the national protocol of Burkina Faso; the control group will receive IFA alone for 6 weeks.

\section{Allocation/randomisation}

We will apply a stratified permuted block randomisation schedule to allocate women to the prenatal intervention or control group and in a next step to allocate women to a postnatal intervention and control group. Per health centre (ie, stratum), women will be individually randomly in permuted blocks of 8 so that, per block, equal numbers are obtained in the prenatal intervention $(n=4)$ and control $(n=4)$ group and equal numbers are also obtained in the postnatal intervention $(n=4)$ and control $(n=4)$ group. The double random sequence will be generated before the start of the study using Stata V.15.1 (Statacorp, Texas, USA) by an external research analyst. The allocation group will be coded with two letters (A or B for the prenatal and $\mathrm{Y}$ or $\mathrm{Z}$ for the postnatal study group) and placed in a sequentially numbered sealed opaque envelopes by project employees, not in direct contact with participants. At study enrolment, the project midwife will draw the next sealed envelope and allocate the participant to the study group defined by the letter code in the envelope. Blinding of participants and community-based project workers will not be possible since the supplements are identifiable. Field staff responsible for measuring primary and secondary study outcomes are not directly involved in the daily supplementation of the study participants and can therefore be considered to be partially blinded.

\section{Outcomes}

Primary outcomes of the RCT

The trial has two primary study outcomes that will be used to assess the impact of the prenatal and the postnatal intervention, respectively:

- Incidence of SGA, defined as birth weight $<10$ th centile of the Intergrowth 21 st reference. ${ }^{29}$

- Length-for-age z-score (LAZ) calculated using the WHO 2006 growth reference at 6 months of age. ${ }^{30}$

\section{Secondary outcomes of the RCT}

A list of the trial's secondary outcomes can be found in table 2.

Birth weight measurements will be defined using the Intergrowth 21st reference, ${ }^{29}$ and child anthropometry will be defined using the Child Growth Standards developed by the WHO. ${ }^{30}$

\section{Outcomes of the substudies}

Substudy 1: impact of the intervention on neonatal and maternal body composition 2-3 weeks after delivery.

Body composition will be determined in motherchild dyads by deuterium dilution and analysis of saliva by a Fourier Transform Infrared reader (Agilent FTIR 4500 series). The substudy will also assess if early gestation maternal BMI (defined as body weight in kilograms divided by the square of height in metres) modifies the intervention's effect on neonatal body composition.

Substudy 2: impact of the intervention on dietary intake.

A dietary assessment study will be conducted, using a 24-hour dietary recall in a subsample of women. This substudy will enable us to assess possible substitution of the prenatal diet by the BEP supplement.

Substudy 3: impact of the intervention on breastmilk.

Breastmilk samples will be taken in the four study groups to compare the composition and to analyse the interaction between the supplementation periods.

\section{Sample size}

With an SGA prevalence of $32 \%$ and an anticipated decrease of $7 \%$, a sample of 652 subjects per prenatal arm is required with $\alpha=0.05$ and $\beta=0.2{ }^{26}$ To accommodate for possible losses, the number of subjects per arm was increased to 888 (total subjects: 1776). Possible losses are based on previous MISAME studies where the prevalence 
Table 2 Secondary outcomes of the RCT on maternal, newborn and child level

\begin{tabular}{ll}
\hline Maternal outcomes & Newborn \\
\hline $\begin{array}{l}\text { Total and trimester-specific prenatal } \\
\begin{array}{l}\text { weight gain and gestational weight } \\
\text { change. }\end{array}\end{array}$ & $\begin{array}{l}\text { Birth weight (measured within } 72 \text { hours after } \\
\text { birth). }\end{array}$ \\
$\begin{array}{l}\text { Probable and possible maternal postnatal } \\
\text { depression at } 2 \text { and } 6 \text { months of child age. }\end{array}$ & birth).
\end{tabular}

\section{Child}

Weight-for-age Z-score at 6 months of age (WAZ) (and 9 and 12 months on a subsample).

Weight-for-length Z-score at 6 months of age (WLZ) (and 9 and 12 months on a subsample).

\begin{tabular}{|c|c|c|}
\hline $\begin{array}{l}\text { Maternal anaemia at the third antenatal } \\
\text { consultation. }\end{array}$ & Ponderal or Rohrer's index at birth. & Stunting at 6 months of age. \\
\hline \multirow{10}{*}{$\begin{array}{l}\text { Women's mean and minimum dietary } \\
\text { diversity score (measured twice weekly). }\end{array}$} & Gestational age at delivery. & Wasting at 6 months of age. \\
\hline & $\begin{array}{l}\text { Chest circumference (measured within } 72 \\
\text { hours after birth). }\end{array}$ & $\begin{array}{l}\text { Duration of exclusive breastfeeding during } \\
\text { the first } 6 \text { months of age. }\end{array}$ \\
\hline & $\begin{array}{l}\text { Arm circumference (measured within } 72 \text { hours } \\
\text { after birth). }\end{array}$ & Weight gain over first 6 months of life. \\
\hline & Incidence of preterm birth. & $\begin{array}{l}\text { Child mortality (between birth and } \\
6 \text { months of age). }\end{array}$ \\
\hline & Fetal loss. & $\begin{array}{l}\text { Monthly change in LAZ over first } 6 \text { months } \\
\text { of life. }\end{array}$ \\
\hline & & $\begin{array}{l}\text { Monthly change in WAZ over first } 6 \text { months } \\
\text { of life. }\end{array}$ \\
\hline & & $\begin{array}{l}\text { Monthly change in head circumference } \\
\text { over first } 6 \text { months of life. }\end{array}$ \\
\hline & & $\begin{array}{l}\text { Child morbidity symptoms over first } \\
6 \text { months of life. }\end{array}$ \\
\hline & & Anaemia at 6 months of age. \\
\hline & & $\begin{array}{l}\text { Haemoglobin concentration at } 6 \text { months } \\
\text { of age. }\end{array}$ \\
\hline
\end{tabular}

LAZ, length-for-age z-score; RCT, randomised controlled trial.

was $\sim 26 \%$ due to a combination of miscarriage, stillbirths, multifetal pregnancies, outmigrants, maternal deaths and incomplete data. ${ }^{18}$ For the analysis of an effect of the postnatal intervention on LAZ at 6 months of age, the minimally detectable effect depends on the presence or absence of an interaction effect between the prenatal and postnatal intervention. In the absence of a statistically significant interaction between prenatal and postnatal intervention, at sample size of 588 children per postnatal study arm would allow us to detect a difference of $0.18 \mathrm{Z}$-score $(\mathrm{SD}=1.1)$ based on a cross-sectional survey conducted in the Gourcy health district in Burkina Faso, ${ }^{31}$ between study arms with $\alpha=0.05$ and $\beta=0.20$. This implies that if $\sim 400$ singleton live births are available, we allow for a maximum loss to follow-up of $16 \%$. In the presence of a statistically significant interaction between prenatal and postnatal intervention, a total sample size of 1176 represents 294 children per factorial combination of the prenatal and postnatal study group (four groups in total). A subgroup size of 294 would allow us to detect a difference in LAZ at 6 months of age of 0.28 assuming an SD of 1.1, $\alpha=0.025$ (Bonferroni correction for two primary endpoints analyses) and $\beta=0.20$.

\section{Data collection}

Anthropometric and clinical procedures

At enrolment, anthropometric measurements from all women will be taken. Gestational age will be determined during an ultrasound consultation by measuring crownrump length (7-13 weeks) or by calculating the mean of three to four measurements: biparietal diameter, head circumference, abdominal circumference and femur length (12-26 weeks). ${ }^{32}$

During pregnancy, clinical follow-up will consist of antenatal visits following the national guidelines.

At birth, anthropometric measurements of all neonates will be assessed in duplicate within the first 72 hours of life (in practice, the aim is to measure within the 24 hours of life). After birth, mother and child will visit the healthcare centres monthly for a follow-up on clinical, 
Table 3 Participant timeline schedule of enrolment, interventions, assessment and visits

\begin{tabular}{|c|c|c|c|c|c|c|c|c|c|c|c|c|c|c|c|}
\hline & \multirow{2}{*}{\multicolumn{2}{|c|}{ Enrolment }} & \multirow[b]{2}{*}{ Allocation } & \multicolumn{12}{|c|}{ Postallocation } \\
\hline & & & & \multicolumn{4}{|c|}{ Pregnancy and birth } & \multicolumn{8}{|c|}{ After birth } \\
\hline & Start & $\begin{array}{l}\text { 5- } \\
\text { weekly } \\
\text { visits }\end{array}$ & ANC 1 & $\begin{array}{l}\text { Household } \\
\text { visit }\end{array}$ & Ultrasound & $\begin{array}{l}\text { ANC } \\
2,3 \\
\text { and } 4\end{array}$ & Birth & $\begin{array}{l}\text { Month } \\
1\end{array}$ & $\begin{array}{l}\text { Month } \\
2\end{array}$ & $\begin{array}{l}\text { Month } \\
3\end{array}$ & $\begin{array}{l}\text { Month } \\
4\end{array}$ & $\begin{array}{l}\text { Month } \\
5\end{array}$ & $\begin{array}{l}\text { Month } \\
6\end{array}$ & $\begin{array}{l}\text { Month } \\
9\end{array}$ & $\begin{array}{l}\text { Month } \\
12\end{array}$ \\
\hline \multicolumn{16}{|l|}{ Enrolment } \\
\hline Census & $x$ & & & & & & & & & & & & & & \\
\hline $\begin{array}{l}\text { Pregnancy } \\
\text { identification }\end{array}$ & & $x$ & & & & & & & & & & & & & \\
\hline $\begin{array}{l}\text { Pregnancy } \\
\text { confirmatory } \\
\text { test }\end{array}$ & & & $x$ & & & & & & & & & & & & \\
\hline $\begin{array}{l}\text { Informed } \\
\text { consent and } \\
\text { allocation to } \\
\text { study group }\end{array}$ & & & $x$ & & & & & & & & & & & & \\
\hline
\end{tabular}

\section{Study groups}

\section{Prenatal}

BEP+IFA

Prenatal IFA

Postnatal

BEP+IFA*

Postnatal IFA

\section{Assessments}

\section{Mothers}

\section{Baseline \\ questionnaire}

Gestational age

determination

\section{Skinfold \\ measurements}

Weight (kg)

and arm

circumference

(mm) †/

\begin{tabular}{|c|c|c|}
\hline Height (cm) & $x$ & \\
\hline $\begin{array}{l}\text { Haemoglobin } \\
(\mathrm{g} / \mathrm{dL})\end{array}$ & $x$ & $\begin{array}{l}\times \\
\text { (ANC3) }\end{array}$ \\
\hline
\end{tabular}

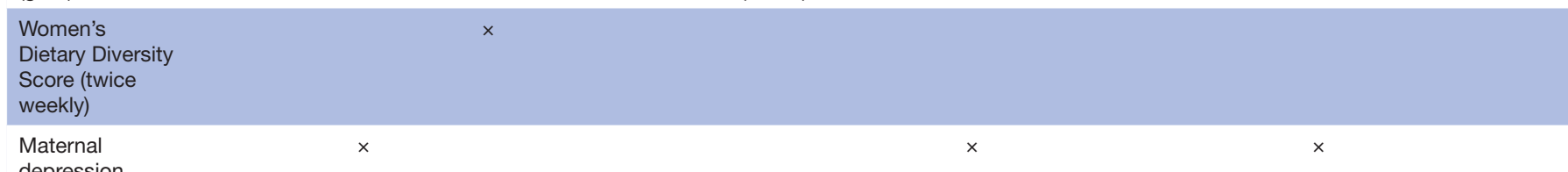

depression

\section{Infants}

Birth weight (kg)

Birth length $(\mathrm{cm})$

Head

circumference

(mm)

\section{Chest \\ circumference \\ (mm)}

Arm

circumference

(mm)

\begin{tabular}{|c|c|c|c|c|c|c|c|c|c|}
\hline Morbidity & & $x$ & $x$ & $x$ & $x$ & $x$ & $x$ & & \\
\hline Mortality & $x$ & $x$ & $x$ & $x$ & $\times$ & $x$ & $x$ & & \\
\hline $\begin{array}{l}\text { Weight }(\mathrm{kg}) \text { and } \\
\text { height }(\mathrm{cm})\end{array}$ & & $x$ & $x$ & $x$ & $x$ & $x$ & $x$ & $x$ & $x$ \\
\hline
\end{tabular}




\begin{tabular}{|c|c|c|c|c|c|c|c|c|c|c|c|c|c|c|}
\hline \multirow{2}{*}{\multicolumn{2}{|c|}{ Enrolment }} & \multirow[b]{2}{*}{ Allocation } & \multicolumn{12}{|c|}{ Postallocation } \\
\hline & & & Pregnancy & nd birth & & & After bi & irth & & & & & & \\
\hline Start & $\begin{array}{l}5- \\
\text { weekly } \\
\text { visits }\end{array}$ & ANC 1 & $\begin{array}{l}\text { Household } \\
\text { visit }\end{array}$ & Ultrasound & $\begin{array}{l}\text { ANC } \\
2,3 \\
\text { and } 4\end{array}$ & Birth & $\begin{array}{l}\text { Month } \\
1\end{array}$ & $\begin{array}{l}\text { Month } \\
2\end{array}$ & $\begin{array}{l}\text { Month } \\
3\end{array}$ & $\begin{array}{l}\text { Month } \\
4\end{array}$ & $\begin{array}{l}\text { Month } \\
5\end{array}$ & $\begin{array}{l}\text { Month } \\
6\end{array}$ & $\begin{array}{l}\text { Month } \\
9\end{array}$ & $\begin{array}{l}\text { Month } \\
12\end{array}$ \\
\hline
\end{tabular}

Breastfeeding

practices

${ }^{*}$ The IFA tablets will be given during the first 6 weeks after birth in the postnatal intervention group, according to the national health protocol. tOnly maternal weight will be taken at birth.

†ln a subsample at months 9 and 12 .

BEP, balanced energy-protein; IFA, iron/folic acid.

anthropometric and child morbidity measures (signs including fever, vomiting, diarrhoea, cough, difficulty breathing and running nose). A subsample will be measured at the healthcare centres or at home by the project interviewers to collect postnatal data at months 9 and 12.

Haemoglobin concentrations will be measured in women at enrolment and during the third antenatal care visit. This will be conducted at 6 months of age among children.

\section{Baseline questionnaires}

Prenatal and postnatal maternal depression will be assessed using the standardised Edinburgh Postnatal Depression Scale questionnaire consisting of 10 questions. ${ }^{33}$ Project midwives will be trained for this, and the questionnaire will be asked at inclusion and at months 2 and 6 after birth. Socioeconomic and demographic information from all participants will be collected once included. Trained project interviewers will ask questions on household members' characteristics, household properties, WASH environment and household food security. ${ }^{34}$ The women's dietary diversity score will be measured in all participating women by the FA during the home visits. This will be enumerated twice a week per participant using the Women's Dietary Diversity Score with 11 food groups. $^{35}$

Table 3 shows the overview of the time schedule and measurements of the trial.

Quality of all study data will be insured by a thorough training of all field staff. Procedures to handle data collection tools (questionnaires, anthropometric and clinical measurement material, and laboratory procedures) will be pretested in the field during a dry-run of \pm 3 months. Anthropometric measurement standardisations of the field staff will be repeated bimonthly throughout the trial. Anthropometric measurements will be taken in duplicate. Newborns will be measured within 72 hours after birth (preferably within the 24 hours), and all weighing scales and HemoCue 201+ devices will undergo weekly quality control. A WhatsApp group will be set up where problems can be communicated and solved quickly.
All data collection forms of the trial can be found on: www.misame3.ugent.be

Women will be designated as lost to follow-up if they move from the study area or withdraw their participation. Reasons for discontinuation will be recorded.

Women will be enrolled in the study from October 2019 until the total sample size has been reached.

\section{Data management and analysis}

FAs will use smartphones with computer-assisted person interviewing programmed in CSPRO (version 7.3.1) to collect data during household visits. The study data collected by the project medical doctor, project midwives and interviewers will be done by Survey Solutions data entry software (V.19.12.6) on tablets. This data will be uploaded to a central server on a weekly basis. All questionnaires were programmed and have been tested on the Survey Solutions Designer website and include validation codes to promote the quality of the data entry in the field. Assignments will be sent once a week to the tablets of the field team, and preloaded data collected at an earlier contact moment will be used to lower the amount of incorrect data. Paper forms will also be available on the field as a backup.

Further data quality checks will be conducted in Stata V.14.2 (Statacorp, Texas, USA). Missing or inconsistent data outliers will be sent back to the field for revision.

\section{Statistical analysis}

We refer to the Statistical Analysis Plan of the trial 'Statistical analysis plan: Impact of a prenatal and postnatal balanced energy-protein supplement on birth size and postnatal child growth in Burkina Faso' published on: www.misame3.ugent. be

\section{Data monitoring}

Data monitoring and auditing

The Data and Safety Monitoring Board is an independent multidisciplinary group whose members are not involved in the trial. The board consists of a Belgian endocrinologist, a Belgian paediatrician, a Burkinabè paediatrician, a Belgian gynaecologist and a Belgian ethicist. 


\section{Serious adverse events (SAEs)}

FAs will be trained to recognise health issues and will actively refer those participants to see the project midwife in the primary health facilities or Centre de Santé et Promotion Sociale (CSPS) in the event they occur. All SAEs will be recorded on a case-by-case basis, and verbal autopsies will be conducted for maternal, neonatal and infant deaths by the field medical doctor.

\section{ETHICS AND DISSEMINATION}

\section{Ethics approval and consent to participate}

MISAME-III has been reviewed and approved by the University Hospital of Ghent University (B670201734334) and the Burkinabe ethics ( $\left.{ }^{\circ} 2018-22 / \mathrm{MS} / \mathrm{SG} / \mathrm{CM} / \mathrm{CEI}\right)$ committee. Important protocol changes will be noted on ClinicalTrials.gov. When eligible women meet the inclusion criteria, project midwives will explain the background and procedure of the complete trial. Written informed consent or assent will be asked from the participating women. In case of illiteracy, a thumb print will be asked and witnessed by the recruiting investigator and one extra witness. Participants will be told that all data collected during the trial is confidential and that they are allowed to withdraw at any time. A copy of the informed consent and assent can be found on www. misame3.ugent.be and as supplementary file (online supplemental file 2).

\section{Patient and public involvement}

MISAME-III has been well accepted by the community, because of the previous positive experiences they had with the MISAME-I and II studies. Through the formative study, women were involved in the choice of BEP supplement. Workshops will be planned at the end of the study in order to communicate the study results to the community.

\section{Ancillary care}

The MISAME-III project will pay for ancillary care when participants have health issues and in case the costs are not covered by the national healthcare programme. Participants suffering harm due to their trial participation will be covered.

\section{Confidentiality}

A data management plan has been put in place to address concerns regarding the General Data Protection Regulation rules. During the trial, the data files containing personal identifying information will be stored on the Survey Solutions server. Only the principal investigators and the project coordinators will be able to access those files.

\section{Dissemination plan}

On completion of the trial, all anonymised study data will be available on request. Final results will be communicated to the participants, the Burkinabè Ministry of health, the field staff, the BMGF, Ghent University researchers and students, AFRICSanté, healthcare professionals and other relevant international public institutions. Papers on the study results will be published in peer-reviewed journals and will be available on the project website. All investigators contributing to the realisation of the project and publication of results will be included as an author. Other contributors such as the participants, FA and field staff members will be mentioned in the acknowledgements.

MISAME-III has been well accepted by the community, because of the previous positive experiences they had with the MISAME-I and II studies. Through the formative study, women were involved in the choice of BEP supplement. Workshops will be planned at the end of the study in order to communicate the study results to the community.

\section{DISCUSSION}

In this paper, the protocol of an individually randomised four-arm efficacy trial in rural Burkina Faso has been described in which pregnant and lactating women in the intervention group will receive a BEP supplement together with IFA tablets. The control group will only receive the standard IFA treatment.

The key features of the present trial are, first, the inclusion of a formative study for a better understanding of which type of supplement is preferred, what taste is most acceptable and which factors affect adherence in the study population. Second, the supplementation will be given during pregnancy and during the first 6 months after birth. This will give us the opportunity to assess the specific value of postnatal supplementation on several outcomes. Third, the observed daily intake of intervention and control supplements is a key feature to ensure compliance and to avoid sharing of the supplements with other household members. Fourth, MISAME-III has the advantage of being the third trial of its kind in the study area. This presents an opportunity to anticipate the issues that arose in previous trials. For instance, women in specific villages tended to leave their homes for a longer period to go work on the fields outside the village. This posed problems in the continuation of the supplementation in the past and will be taken into consideration during MISAME-III. Fourth, four substudies are nested in the main trial that will provide insight into the mechanism by which prenatal BEP supplementation affects birth and infant outcomes. And last, similar studies are being conducted in other countries, allowing for comparison between results from different contexts.

The MISAME-III study will provide evidence on the impact of BEP supplements on birth and infant size using a rigorous study design. The study results will further strengthen and refine WHO's recommendation on the use of context-specific BEP supplementation during pregnancy and lactation. 


\section{Author affiliations}

${ }^{1}$ Department of Food Technology, Safety and Health, Faculty of Bioscience Engineering, Ghent University, Gent, Belgium

${ }^{2}$ Institut de Recherche en Sciences de la Sante, Bobo-Dioulasso, Burkina Faso ${ }^{3}$ AFRICSanté, Bobo Dioulasso, Burkina Faso

${ }^{4}$ Poverty, Health and Nutrition Division, International Food Policy Research Institute, Washington, DC, USA

Acknowledgements The Mlcronutriments pour la SAnté de la Mère et de I'Enfant (MISAME) Study Group would like to thank the pregnant women and their families for the time spent in this study. We would like to acknowledge the staff of AFRICSanté; including Henri Somé for his support on the computer-assisted person interviewing software, the field medical Dr Anderson Compaoré, the data collectors (midwives, interviewers and femmes accompagnantes), Dr Alain Hein for the standardisation exercises and Dr Hermann Lanou for his support during the training. We would like to thank Dr Sheila Isanaka for her collaboration during the formative research. Our private sector partner Nutriset (France) is acknowledged for donating the balanced energy-protein supplements.

Contributors KV wrote the manuscript; PK, LH, CL, NDC, LCT, KV, BdK, TD-C and GHC designed the study and the protocol; PK, LH, LCT, KV and BdK designed the study material tools; LCT, LH, KV, BdK, MO and RG trained the field data collectors; TD-C and GHC critically reviewed and revised the manuscript; all authors contributed substantially to the manuscript and approved the final version.

Funding This work was funded by the Bill and Melinda Gates Foundation. Grant number OPP1175213. The trial is registered on Clinical Trials.gov (identifier: NCT03533712) prior to recruitment. Enrolment started in October 2019.

Competing interests None declared.

Patient consent for publication Not required.

Provenance and peer review Not commissioned; externally peer reviewed.

Supplemental material This content has been supplied by the author(s). It has not been vetted by BMJ Publishing Group Limited (BMJ) and may not have been peer-reviewed. Any opinions or recommendations discussed are solely those of the author(s) and are not endorsed by BMJ. BMJ disclaims all liability and responsibility arising from any reliance placed on the content. Where the content includes any translated material, BMJ does not warrant the accuracy and reliability of the translations (including but not limited to local regulations, clinical guidelines, terminology, drug names and drug dosages), and is not responsible for any error and/or omissions arising from translation and adaptation or otherwise.

Open access This is an open access article distributed in accordance with the Creative Commons Attribution 4.0 Unported (CC BY 4.0) license, which permits others to copy, redistribute, remix, transform and build upon this work for any purpose, provided the original work is properly cited, a link to the licence is given, and indication of whether changes were made. See: https://creativecommons.org/ licenses/by/4.0/.

\section{ORCID iDs}

Katrien Vanslambrouck http://orcid.org/0000-0003-1746-7056

Brenda de Kok http://orcid.org/0000-0002-5267-327X

Laeticia Celine Toe http://orcid.org/0000-0002-4615-5388

Nathalie De Cock http://orcid.org/0000-0002-0053-0269

Moctar Ouedraogo http://orcid.org/0000-0002-1521-0532

Trenton Dailey-Chwalibóg http://orcid.org/0000-0002-8204-4925

Giles Hanley-Cook http://orcid.org/0000-0001-9907-594X

Rasmané Ganaba http://orcid.org/0000-0001-7401-9546

Carl Lachat http://orcid.org/0000-0002-1389-8855

Lieven Huybregts http://orcid.org/0000-0002-3068-2853

Patrick Kolsteren http://orcid.org/0000-0002-0504-2205

\section{REFERENCES}

1 Lee ACC, Katz J, Blencowe $\mathrm{H}$, et al. National and regional estimates of term and preterm babies born small for gestational age in 138 lowincome and middle-income countries in 2010. Lancet Glob Health 2013;1:e26-36.

2 Katz J, Lee AC, Kozuki N, et al. Mortality risk in preterm and small-for-gestational-age infants in low-income and middle-income countries: a pooled country analysis. Lancet 2013;382:417-25.

3 van Rossum CTM, Fransen HP, Verkaik-Kloosterman J, et al. Dutch national food consumption survey 2007-2010: diet of children and adults aged 7 to 69 years, 2011.
4 Lee AC, Kozuki N, Cousens S, et al. Estimates of burden and consequences of infants born small for gestational age in low and middle income countries with INTERGROWTH-2 $21^{\text {st }}$ standard: analysis of CHERG datasets. BMJ 2017;358:j3677.

5 Stevens B, Buettner P, Watt K, et al. The effect of balanced protein energy supplementation in undernourished pregnant women and child physical growth in low- and middle-income countries: a systematic review and meta-analysis. Matern Child Nutr 2015;11:415-32

6 WHO. WHO recommendations on antenatal care for a positive pregnancy experience. World Health Organization, 2016.

7 Krishna U, Bhalerao S. Placental insufficiency and fetal growth restriction. J Obstet Gynaecol India 2011;61:505-11.

8 Mridula D, Mishra C, Chakravorty A. Dietary intake of expectant mother. Indian J Nutr Diet 2003;40:24-30.

9 Tang AM, Chung M, Dong K. Determining a global mid-upper arm circumference cutoff to assess malnutrition in pregnant women. Food and Nutrition Technical Assistance, 2016

10 Branca F, Grummer-Strawn L, Borghi E, et al. Extension of the WHO maternal, infant and young child nutrition targets to 2030. SCN News 2015;41:55-8.

11 Keats EC, Haider BA, Tam E, et al. Multiple-micronutrient supplementation for women during pregnancy. Cochrane Database Syst Rev 2019;3:CD004905.

12 Hambidge KM, Westcott JE, Garcés A, et al. A multicountry randomized controlled trial of comprehensive maternal nutrition supplementation initiated before conception: the women first trial. Am J Clin Nutr 2019:109:457-69.

13 Ota E, Hori H, Mori R. Antenatal dietary education and supplementation to increase energy and protein intake. Cochrane Database Syst Rev 2015;6:CD000032.

14 Imdad A, Bhutta ZA. Maternal nutrition and birth outcomes: effect of balanced protein-energy supplementation. Paediatr Perinat Epidemiol 2012;26:178-90.

15 Kramer MS, Kakuma R. Energy and protein intake in pregnancy. Cochrane Database of Syst Rev 2003;4.

16 Bill and Melinda Gates Foundation (BMGF). Framework and specifications for the nutritional composition of a food supplement for pregnant and lactating women (PLW) in undernourished and lowincome settings. Expert consultation Seatle, US, 2016.

17 Roberfroid D, Huybregts L, Lanou H, et al. Effects of maternal multiple micronutrient supplementation on fetal growth: a doubleblind randomized controlled trial in rural Burkina Faso. Am J Clin Nutr 2008;88:1330-40.

18 Huybregts L, Roberfroid D, Lanou H, et al. Prenatal food supplementation fortified with multiple micronutrients increases birth length: a randomized controlled trial in rural Burkina Faso. Am J Clin Nutr 2009;90:1593-600.

19 United Nations Development Programme. Human development reports [online], 2019. Available: http://hdr.undp.org/en/countries/ profiles/BFA

20 Unicef. The state of the world's children: children with disabilities: UN, 2013.

21 MEASURE DHS, ICF Macro. Enquête démographique et de santé et indicateurs multiples (EDSBF-MICS IV), Rapport préliminaire, Burkina Faso, 2010. Ouagadougou: INSD, 2011.

22 Institut National de la Statistique et de la Démographie (INSD) et ICF International. Enquête Démographique et de Santé et Indicateurs multiples Du Burkina Faso 2010. Calverton, Maryland: INSD et ICF International, 2012

$23 \mathrm{MOH}$. National iodine status and anemia survey, Burkina Faso, 2014.

$24 \mathrm{MOH}$. MdIS. Enquête Nutritionnelle Nationale 2013, 2013.

25 Savy M, Martin-Prével Y, Sawadogo P, et al. Use of variety/diversity scores for diet quality measurement: relation with nutritional status of women in a rural area in Burkina Faso. Eur J Clin Nutr 2005;59:703-16.

26 Huybregts LF, Roberfroid DA, Kolsteren PW, et al. Dietary behaviour, food and nutrient intake of pregnant women in a rural community in Burkina Faso. Matern Child Nutr 2009;5:211-22.

27 Jones L, de Kok B, Moore K, et al. Acceptability of 12 fortified balanced energy protein supplements - Insights from Burkina Faso. Matern Child Nutr 2021;17:e13067.

28 de Kok B, Moore K, Jones L. Acceptability and at-home consumption of two fortified balanced energy-protein supplements among pregnant women in rural Burkina Faso: a mixed methods study. Matern Child Nutrit 2021;17:e13067.

29 Villar J, Altman DG, Purwar M, et al. The objectives, design and implementation of the INTERGROWTH-21st project. BJOG 2013;120:9-26.

30 de Onis M, Branca F. Childhood stunting: a global perspective. Matern Child Nutr 2016;12:12-26. 
31 Becquey E, Huybregts L, Zongrone A, et al. Impact on child acute malnutrition of integrating a preventive nutrition package into facilitybased screening for acute malnutrition during well-baby consultation: a cluster-randomized controlled trial in Burkina Faso. PLoS Med 2019;16:e1002877.

32 Salomon LJ, Alfirevic Z, Da Silva Costa F, et al. ISUOG practice guidelines: ultrasound assessment of fetal biometry and growth. Ultrasound Obstet Gynecol 2019;53:715-23.
33 Cox JL, Holden JM, Sagovsky R. Detection of postnatal depression. development of the 10-item Edinburgh postnatal depression scale. Br J Psychiatry 1987;150:782-6.

34 Femi A. Perception of performance appraisal and workers' performance in Wema Bank Headquarters, Lagos. Global J Arts Human Soc Sci 2013;1:89-101.

35 Martin-Prével Y, Allemand P, Wiesmann D, et al. Moving forward on choosing a standard operational indicator of women's dietary diversity. FAO, 2015. 